\title{
Fístula axilo-cava para hemodiálise: relato de caso
}

\author{
Axillary arteriovenous fistula for hemodialysis: case report \\ Yosio Nagato, Carmen Neuda Alves Calixto, Marcelo Luiz Brandão, Luís Cavalcante Nagato, \\ Guilherme de Oliveira Bessa, Leôncio Caetano Rodrigues Neto, Luciana Mara Nogueira Fonseca*
}

\section{Resumo}

Na confecção de fístula arteriovenosa (FAV) para hemodiálise, condutos venosos autógenos demonstram performance superior quando comparados com material protético em relação à perviedade primária ou secundária. A prótese de politetrafluoroetileno (PTFE) é reservada para casos de falência de material autógeno e é geralmente utilizada em fístulas em membros superiores. Descrevemos o caso de uma paciente de 52 anos que, após falência de acessos para hemodiálise e impossibilidade de realização de diálise peritoneal em razão de peritonite bacteriana, foi submetida à confecção de FAV entre a artéria axilar direita e a veia cava inferior com prótese de PTFE de $6 \mathrm{~mm}$. O acesso foi utilizado para hemodiálise 1 mês após sua criação e permanece pérvio após 24 meses. Até o momento, não houve complicações infecciosas, sinais de insuficiência cardíaca ou síndrome de roubo em membro superior direito.

Palavras-chave: Fístula arteriovenosa, falência de acesso, prótese de PTFE.

\section{Introdução}

Atualmente, é consenso que, para a hemodiálise, a fístula arteriovenosa (FAV) autóloga apresenta melhores resultados a médio e longo prazo quando comparada com outros substitutivos vasculares, inclusive o enxerto de politetrafluoroetileno (PTFE), tanto em relação à perviedade quanto ao índice de complicações pós-operatórias ${ }^{1-3}$.

As complicações do acesso vascular são as principais causas de hospitalização dos pacientes em regime de diáli$\mathrm{se}^{4,5}$. Nos EUA, a prevalência estimada é de 373 pacientes a cada milhão de habitantes ${ }^{6}$, representando essas complicações $20 \%$ do total de gastos com hemodiálise ${ }^{7}$.

$\mathrm{O}$ acesso vascular ideal é aquele que possui um fluxo sanguíneo satisfatório, meia-vida longa e baixo índice de complicações. Na Europa, a FAV autóloga é considerada como primeira opção de acesso vascular definitivo e utilizada por cerca de 80 a $90 \%$ dos pacientes, enquanto nos EUA, a FAV autóloga representa apenas 20 a 30\% do total

\begin{abstract}
With regards to the creation of an arteriovenous fistula (AV fistula) for hemodialysis, autogenous venous grafts clearly show high performance when compared with prosthetic material in terms of primary or secondary patency. Polytetrafluoroethylene (PTFE) grafts for the reconstruction of AV fistulae must be restricted to cases of failure of the autogenous material, which is generally used in upper limb fistulae. We describe a case of a 52-year-old patient, who, after access failure for hemodialysis and the impossibility of performing peritoneal dialysis due to bacterial peritonitis, underwent the reconstruction of an AV fistula between the right axillary artery and the cava vein using a 6-mm PTFE prosthesis. One month after surgery, this AV fistula started to be used for hemodialysis. The AV fistula remains patent 24 months after its creation. No infectious complications, cardiac insufficiency symptoms, or steal syndromes of right upper limb were detected.
\end{abstract}

Keywords: Arteriovenous fistula, access failure, PTFE graft.

de $\operatorname{casos}^{8}$. Neste país, os gastos com acesso vascular chegam a representar $25 \%$ dos recursos destinados à terapia renal substitutiva, e estudos têm demonstrado redução progressiva na utilização de próteses na última década, motivada principalmente pelos altos custos operacionais ${ }^{9}$. Também no Brasil o acesso vascular inicial preferido é a FAV autóloga, sendo que o uso de prótese para diálise gira em torno de $2 \%$ dos $\operatorname{casos}^{10}$. As desvantagens do uso de veia autógena são a necessidade de vasos de maior calibre e de maior tempo de maturação (de 4 a 16 semanas), enquanto o PTFE pode ser usado em até 1 semana após a implantação. No entanto, este enxerto tem menor sobrevida, em função de estenose ou trombose, e maior morbidade devido à maior possibilidade de infecção.

A opção pela prótese (geralmente PTFE) é reservada aos pacientes nos quais as tentativas de confecção de uma FAV autóloga foram mal sucedidas, ou quando esse insucesso é antecipado pelas condições desfavoráveis do leito

\footnotetext{
* Serviço de Cirurgia Vascular, Hospital das Clínicas, Universidade Federal de Goiás, Goiânia, GO.

Não foram declarados conflitos de interesse associados à publicação deste artigo.

Artigo submetido em 10.09.08, aceito em 13.10.09.

J Vasc Bras. 2009;8(4):371-373.

Copyright @ 2009 by Sociedade Brasileira de Angiologia e de Cirurgia Vascular
} 
vascular, o que é mais frequente em idosos, obesos e diabéticos.

\section{Descrição do caso}

Descrevemos o caso de uma paciente de 52 anos, do sexo feminino, hipertensa, diabética, portadora de nefroesclerose hipertensiva, em regime de hemodiálise há 6 anos. Ao longo desse período, foram utilizados acessos habituais como cateteres centrais e FAV em membros superiores e inferiores. Após falência desses acessos e impossibilidade de realização de diálise peritoneal devido a peritonite bacteriana, foi submetida a ultrassonografia (USG) para avaliação de território para confecção de nova FAV. O exame revelou oclusão de veias jugulares internas e externas, espessamento acentuado de veias subclávias direita e esquerda, oclusão com trombose de veias femorais comuns à direita e à esquerda e veia cava inferior pérvia. Assim, optou-se por confecção de FAV entre a artéria axilar direita e a veia cava inferior com prótese de PTFE de $6 \mathrm{~mm}$, conforme figuras a seguir.

Sob anestesia geral, a FAV axilo-cava foi confeccionada com dissecção da artéria axilar direita (terço proximal) e acesso retroperitoneal direito para dissecção da veia cava infrarrenal. Foi realizado túnel subcutâneo na linha axilar anterior e passagem da prótese de PTFE de $6 \mathrm{~mm}$. Em ambas as anastomoses, a técnica utilizada foi sutura contínua com fio prolene cardiovascular 6-0 término lateral.

Depois de 1 mês da implantação, foi iniciada hemodiálise por este acesso, o qual permanece funcionante até o momento atual (24 meses após sua confecção). Não se evidenciaram complicações infecciosas, sinais de insuficiência cardíaca ou síndrome de roubo no membro superior direito.

\section{Discussão}

No Brasil, no ano de 2006, havia cerca de 86.284 pacientes com insuficiência renal crônica terminal tratados através dos diferentes procedimentos dialíticos. A prevalência de pacientes em regime de diálise atendidos no SUS naquele ano foi de 46,20 casos por 100.000 habitantes. As taxas são mais elevadas entre os homens e aumentam conforme a idade, passando de 13,11 por 100.000 habitantes na faixa etária de menos de 30 anos para 184,07 entre os que têm mais de 60 anos $^{11}$. $\mathrm{O}$ aumento do número absoluto de pacientes foi de $3,9 \%$ entre 2006 e $2007^{12}$.

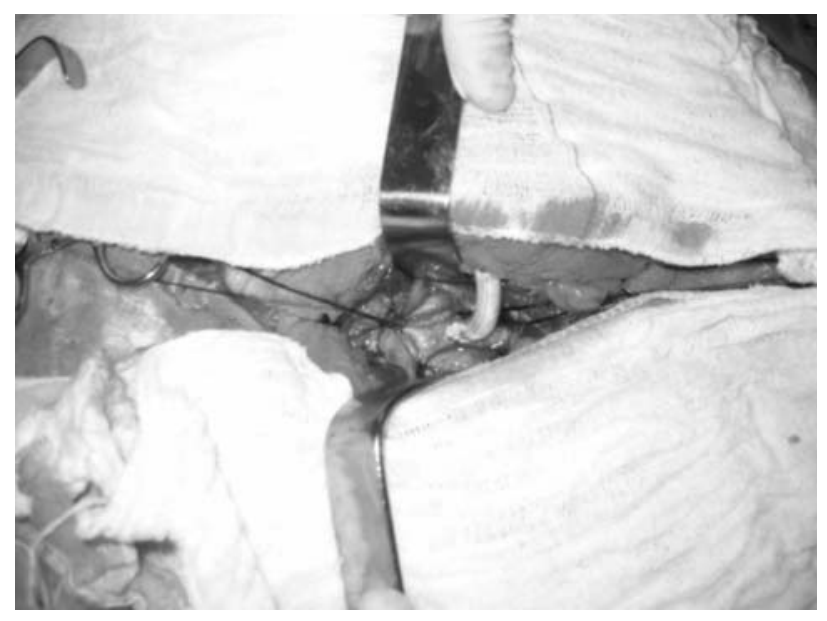

Figura 1 - Anastomose término-lateral entre prótese de politetrafluoroetileno $6 \mathrm{~mm}$ e artéria subclávia direita

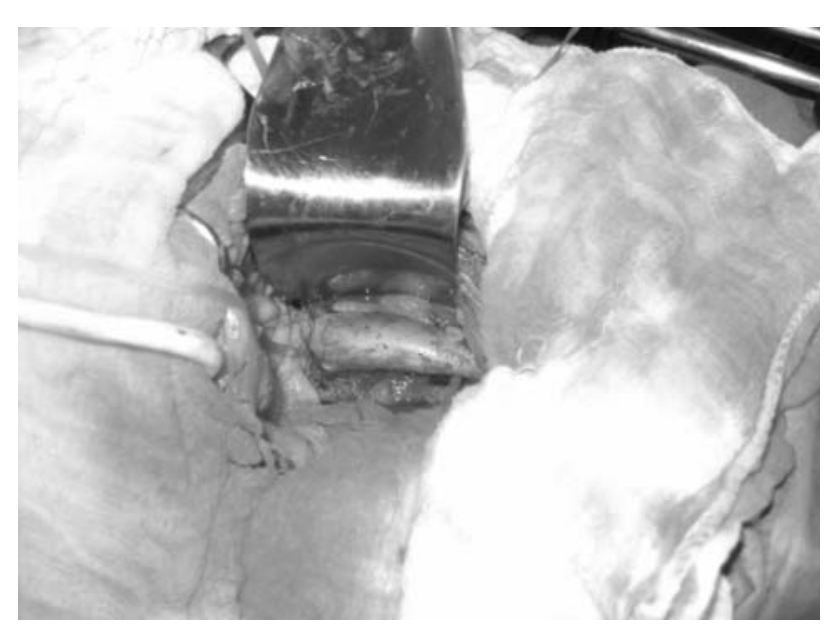

Figura 2 - Veia cava isolada

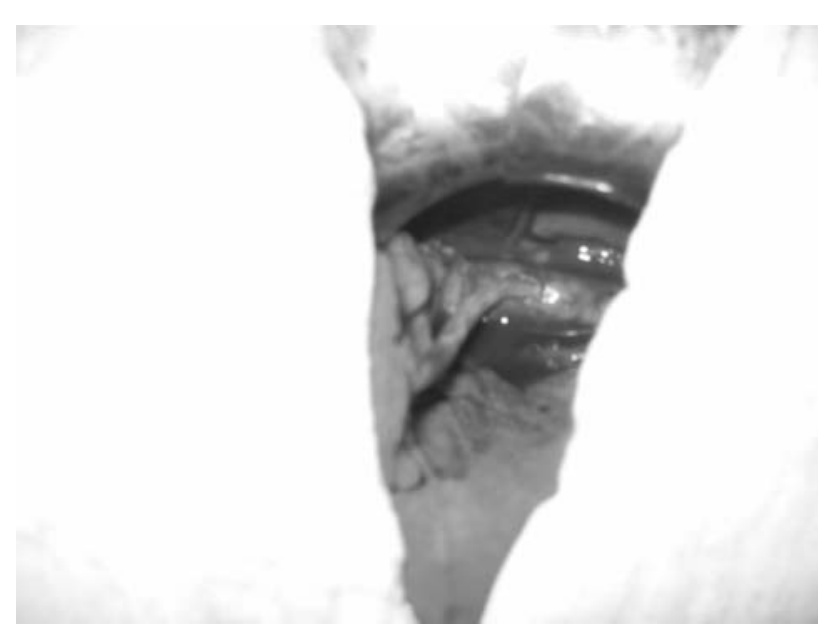

Figura 3 - Anastomose término-lateral entre prótese de politetrafluoroetileno $6 \mathrm{~mm}$ e veia cava 
$\mathrm{O}$ aumento progressivo de pacientes que necessitam de hemodiálise por tempo prolongado faz com que a confecção de acessos vasculares se torne uma prática comum. Alguns pacientes com doença renal crônica não apresentam veias disponíveis para confecção de FAV, sendo então necessária, nesses casos, a utilização de material sintético.

Esgotadas, portanto, as possibilidades de FAV autóloga, o enxerto com PTFE geralmente é implantado como alça no braço ou antebraço, ou mesmo como ponte reta braquioaxilar. Os territórios cirúrgicos, na grande maioria dos casos, são os membros superiores. As coxas são opções menos aceitas pelo maior risco de infecção. O sucesso do procedimento requer fluxo arterial e efluxo venoso adequados. Rotação ou angulação da prótese deve ser evitada.

As complicações mais comuns dos acessos vasculares definitivos para hemodiálise compreendem a trombose da fistula, a infecção, a hipertensão venosa e a degeneração aneurismática ${ }^{13,14}$. A falência precoce das fístulas por trombose é uma limitação. Estudos pequenos e inconclusivos têm sugerido que o uso de antiplaquetários pode reduzir o risco de trombose ${ }^{15}$.

Em revisão de literatura, observamos a escassez de material nacional acerca do uso de próteses para casos de falência de acesso para hemodiálise e das diferentes opções de FAV que podem ser confeccionadas. Neste relato, apresentamos uma alternativa de abordagem a ser considerada quando necessário.

Relatamos uma alternativa possível em casos graves de falência de acesso uma vez esgotadas as opções habituais, com boa perviedade após 24 meses da cirurgia.

\section{Referências}

1. Aguiló JM, Galleguillos IO, Rodríguez OO. Accesos vasculares para hemodiálisis: experiencia con PTFE. Rev Chil Cir. 1992;44:451-4.

2. Herskovic J, Kappes J, Ramírez M, Seitz JC. Accesos vasculares: consejos para su construcción y manejo. Rev Hosp Clin Univ Chile. 1993;4:54-6.

3. Sánchez AH. Accesos vasculares para hemodiálisis. Cuad Cir. 1994;8:31-7.

4. Marques AB, Pereira D, Ribeiro RCHM. Motivos e frequência de internação dos pacientes com IRC em tratamento hemodialítico. Arq Cienc Saude. 2005;12:67-72.

5. Coronel F, Herrero JA, Mateos P, Illescas ML, Torrente J, del Valle MJ. Long-term experience with the Thomas shunt, the forgotten permanent vascular access for haemodialysis. Nephrol Dial Transplant. 2001;16:1845-9.

6. United States Renal Data System - USRDS [site na internet]. USRDS Coordinating Center, Minneapolis, United States. [citado 2008 mar 10]. http://www.usrds.org/reference.htm/.

7. Añel RL, Yevzlin AS, Ivanovich P. Vascular access and patient outcomes in hemodialysis: questions answered in recent literature. Artif Organs. 2003;27:237-41.

8. Pisoni RL, Young EW, Dykstra DM, et al. Vascular access use in Europe and the United States: results from the DOPPS. Kidney Int. 2002;61:305-16.

9. Gibson KD, Caps MT, Kohler TR, et al. Assessment of a policy to reduce placement of prosthetic hemodialysis access. Kidney Int. 2001;59:2335-45.

10. Sesso R. Inquérito epidemiológico em unidades de diálise do Brasil. J Bras Nefrol. 2000;22:23-6

11. Brasil, Ministério da Saúde, Departamento de Informática do SUS. DATASUS [site na internet] http://www.datasus.gov.br/datasus/datasus.php

12. Sesso R, Lopes AA, Thomé FS, Bevilacqua JL, Romão Junior JE, Jocemir L. Resultados do censo de diálise da SBN, 2007. J Bras Nefrol. 2007;29:197-202.

13. Chávez AA, Silva JCS, Díaz PD, Huilcamán MP, Pizarro CS. Complicaciones de los accesos vasculares para hemodiálisis. Bol Hosp Vina del Mar. 2003;59:145-54.

14. de Cortázar LG, Gutiérrez E, Delucchi MA, Cumsille MA. Vascular accesses for chronic hemodialysis in children. Rev Med Chil. 1999;127:693-7.

15. Dember LM, Beck GJ, Allon M, et al. Effect of clopidogrel on early failure of arteriovenous fistulas for hemodialysis: a randomized controlled trial. JAMA. 2008;299:2164-71.

Correspondência:

Luciana Mara Nogueira Fonseca

Rua C-253, Qd. 572, Lt. 24 Setor Nova Suíça

CEP 74280-170 - Goiânia, GO

Tel.: (62) 3091.6290, (62) 8121.8331

E-mail: lumaranogueira@hotmail.com

\section{Contribuições dos autores}

Concepção e desenho do estudo: LMNF, GOB

Análise e interpretação dos dados: YN, LCN

Coleta de dados: LMNF, GOB

Redação do artigo: LMNF, GOB

Revisão crítica do texto: LCN, YN, CNAC, MLB, LCRN

Aprovação final do artigo*: YN, LCN, CNAC, MLB, LMNF, GOB, LCRN

Análise estatística: N/A

Responsabilidade geral pelo estudo: YN, LCN

*Todos os autores leram e aprovaram a versão final submetida ao J Vasc Bras 